\title{
Effects of March 20, 2015, partial ( $50 \%)$ solar eclipse on meteorological parameters in the urban area of Naples (Italy)
}

\author{
Nicola Scafetta, Adriano Mazzarella*
}

Osservatorio Meteorologico, Università di Napoli Federico II, DiSTAR, Naples, Italy

\author{
Article history \\ Received November 3, 2015; accepted January 11, 2016. \\ Subject classification: \\ Radiation, Solar-terrestrial interaction, Meteorological effects of an eclipse.
}

\section{ABSTRACT}

During the partial ( 50\%) solar eclipse occurred on March 20, 2015, morning, various meteorological parameters were monitored to study their evolution above the urban area of Naples, central Italy. The experimental conditions were optimal because of the clear sky situation all over Italy, and in Naples in particular. The eclipse last about 2 hours between 9:25:06 (UT+1, local Italian time) and 11:43:09 (local Italian time, $U T+1)$. From the observation site, the incoming solar radiation diminished by about 50\% at the eclipse peak at 10:32:18 (local Italian time, $U T+1)$, as expected. On the contrary, the UV radiation diminished significantly less, about $25 \%$. This frequency response was likely due to Rayleigh scattering. It suggests that about $50 \%$ of the UV radiation reaching the surface was direct light and 50\% scattered light. During the eclipse, the urban surface temperature and humidity values stayed almost constant instead of increasing and decreasing, respectively, as predicted by their daily cycle. This result was used to estimate that the average emissivity of the city of Naples is about $\varepsilon=0.86$. The wind speed decreased significantly during the event while the atmospheric pressure stayed constant to decrease only after the eclipse. Finally, we propose a simple empirical method to approximately estimate the cooling effect of an eclipse, which meteorologists could use to correct the temperature model forecast that normally ignores the occurrence of an eclipse. Consistency of these results with the literature and its importance is briefly discussed.

\section{Introduction}

Meteorologists have found solar eclipses attractive for studying the response of the atmosphere under the peculiar condition of an abrupt change of the incident solar radiation [Zerefos et al. 2007]. Numerous studies have reported abrupt changes in meteorological parameters such as surface temperature, humidity, wind speed intensity and direction and atmospheric pressure [Anbar 2006, Founda et al. 2007, Zerefos et al. 2007, Muraleedharan et al. 2010, and references therein]. Also direct effects of a solar eclipse on solar and UV surface radiation have been typically studied for better understanding the interaction between the solar irradiance spectrum and the atmosphere [Kazadzis et al. 2007, Kazantzidis et al. 2007, Tzanis et al. 2008]. The response of the atmosphere to an eclipse event strongly depends on the local coordinates, geography and meteorological conditions. Studying total and partial eclipses is equally important for a better understanding of the phenomenon.

On March 20, 2015, an equinoctial solar eclipse occurred from 7:40 UT to 11:50 UT. The eclipse peak occurred around 9:46 UT on the ocean between Iceland and Norway (lat. $64^{\circ} 25^{\prime} 54^{\prime \prime} \mathrm{N}$, lon. $6^{\circ} 38^{\prime} 48^{\prime \prime} \mathrm{W}$ ). Figure 1 depicts the eclipse path map and summarizes its timing and other relevant geographical and astronomical information. The eclipse was mostly visible from the North Sea, the Faeroe Islands and Svalbard, and it was partially visible throughout Europe. In Italy, the Sun was obscured by $39 \%$ to $67 \%$ depending on the latitude and longitude of the observation: see Figure 2. Herein, we are interested in studying the meteorological changes in the urban area of Naples, on the west coast of central Italy, during the March 20, 2015, partial eclipse where a nearly $50 \%$ solar eclipse was observed, and to use this information to deduce a general meteorological response to an eclipse.

\section{Data analysis and physical implications}

Table 1 reports the timing and obscuration percent of the eclipse as seen in major Italian cities. During March 20, 2015, most Italy benefited of meteorological conditions favorable to study the meteorological consequences of the eclipse because of the sunny and cloud-free sky weather. Figure 2 shows the weather forecast for the day and the result is confirmed in Figure 3 by the high pressure $(1020-1025 \mathrm{hPa})$ and temperature of the day that were higher than the seasonal average present throughout the Italian peninsula and throughout most of West Europe. This favorable condition could be used to deduce how an eclipse could in- 


\section{Total Solar Eclipse of 2015 Mar 20}

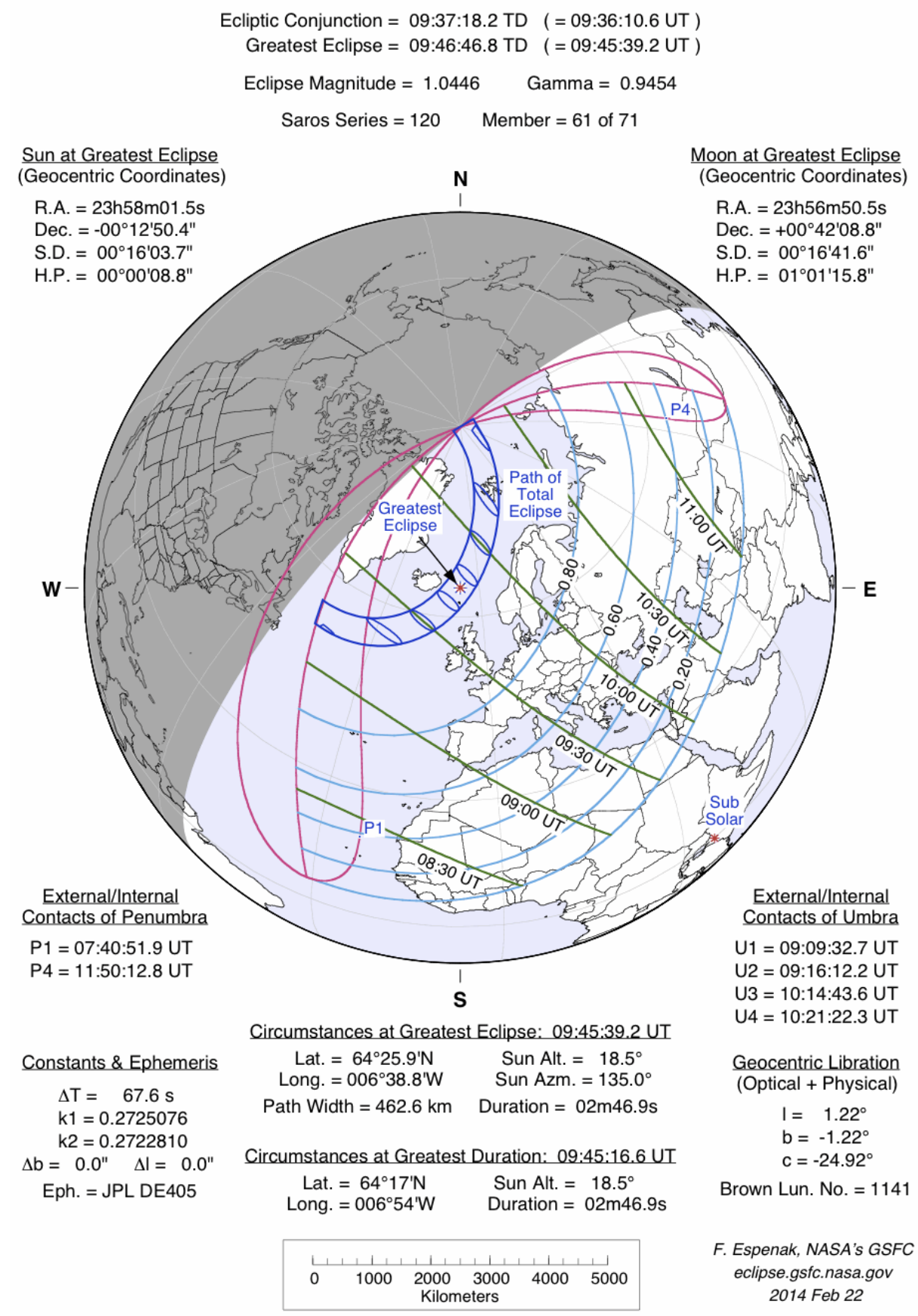

Figure 1. Map of the March 20, 2015, eclipse path on Earth. Total eclipse is visible within the dark blue areas; partial eclipse is visible within the light blue areas. The eclipse occurs at sunrise or sunset in the pink areas. Light blue lines represent a constant fixed fraction of coverage. Green lines show the time for greatest coverage. Figure from http:/ / eclipse.gsfc.nasa.gov/SEplot/SEplot2001/SE2015Mar20T.GIF.

fluence meteorological parameters.

Figure 4 shows a series of photographs of the various phases of the eclipse as observed in Pescara (lat. $42^{\circ} 27^{\prime} 51^{\prime \prime} \mathrm{N}$, long. $\left.14^{\circ} 12^{\prime} 51^{\prime \prime} \mathrm{E}\right)$, which is located in central Italy on the Adriatic sea. As reported in Table 1, in this location the eclipse started at 9:26:50 (UT+1, local time) and ended at 11:45:56 (UT+1, local time). In Pescara, the Sun's maximum obscuration was about $53 \%$, like in Rome, at 10:34:38 (UT+1, local time). Thus, central Italy was an optimal location for study- ing the meteorological response under the specific condition of an abrupt decrease of incident solar radiation by about $50 \%$. However, the specific $50 \%$ condition was better met by the city of Naples, where the eclipse screening was $49.40 \%$ (Table 1). In the following we study what happened in Naples.

Data were collected at the Meteorological Observatory of the University of Naples Federico II [Palumbo and Mazzarella 1984, Di Cristo et al. 2007, Mazzarella and Giuliacci 2011]. ${ }^{(1)}$ Meteorological data are currently col- 

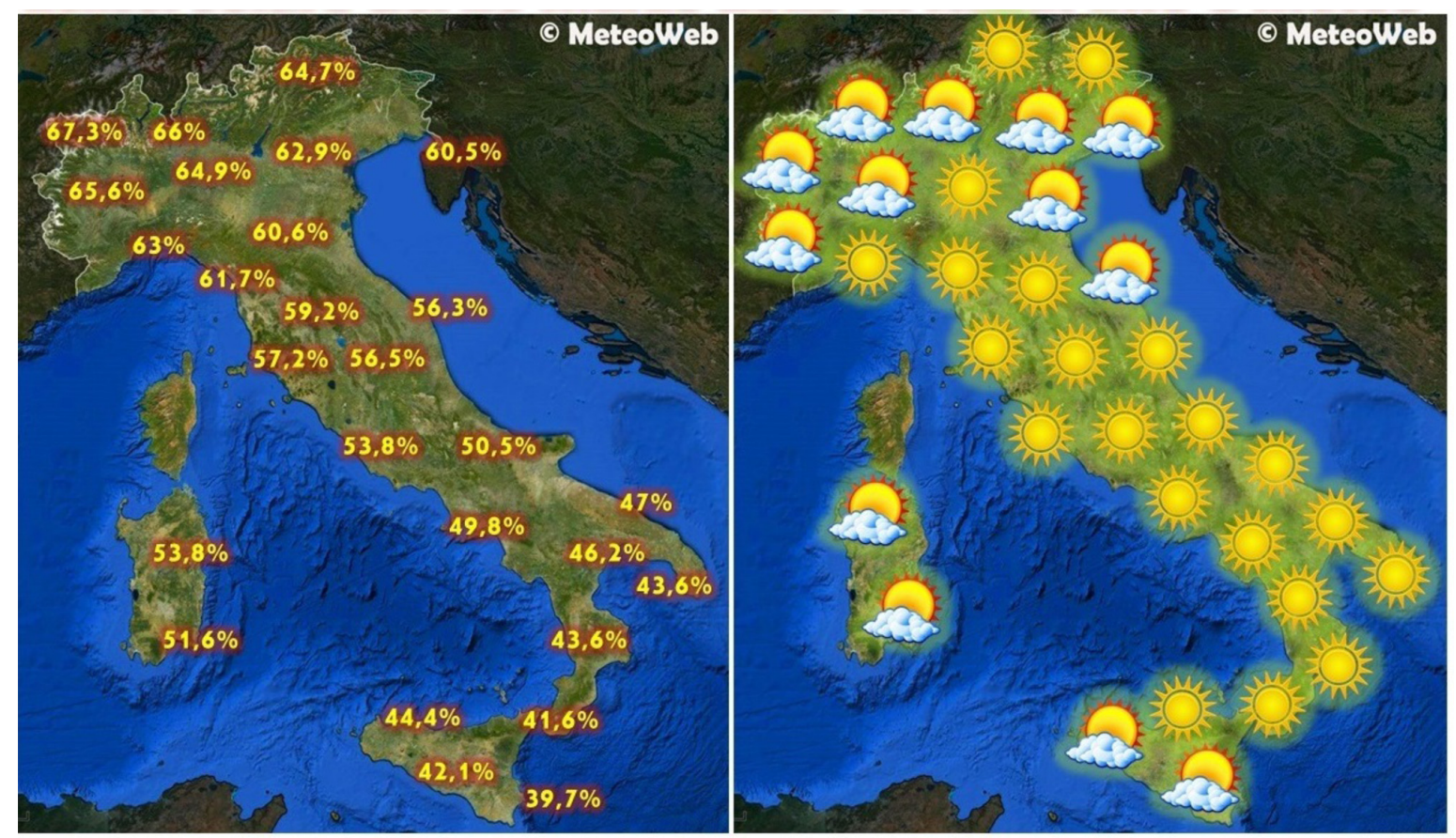

Figure 2. (Left) Percent of the Sun's dimming (see also Table 1), and (Right) meteorological conditions in Italy on March 20, 2015. Figure from http:/ /www.meteoweb.eu.

\begin{tabular}{|c|c|c|c|c|c|c|}
\hline \multirow{2}{*}{ City } & \multicolumn{2}{|c|}{ Coordinates } & \multirow{2}{*}{$\begin{array}{l}\text { Beginning } \\
(\mathrm{UT}+1)\end{array}$} & \multirow{2}{*}{$\begin{array}{l}\text { Maximum } \\
(\mathrm{UT}+1)\end{array}$} & \multirow{2}{*}{$\begin{array}{c}\text { End } \\
(\mathrm{UT}+1)\end{array}$} & \multirow{2}{*}{$\begin{array}{c}\text { Sun's } \\
\text { dimming }\end{array}$} \\
\hline & Latitude & Longitude & & & & \\
\hline Aosta & $45^{\circ} 44^{\prime} 14^{\prime \prime} \mathrm{N}$ & $7^{\circ} 19^{\prime} 14^{\prime \prime} \mathrm{E}$ & $9: 22: 32$ & 10:30:11 & $11: 41: 58$ & $67.32 \%$ \\
\hline Turin & $45^{\circ} 04^{\prime} 00^{\prime \prime} \mathrm{N}$ & $7^{\circ} 42^{\prime} 00^{\prime \prime} \mathrm{E}$ & 9:21:59 & $10: 29: 36$ & $11: 41: 24$ & $65.62 \%$ \\
\hline Milan & $45^{\circ} 27^{\prime} 51^{\prime \prime} \mathrm{N}$ & $9^{\circ} 11^{\prime} 25^{\prime \prime} \mathrm{E}$ & $9: 24: 13$ & 10:32:09 & 11:44:03 & $64.88 \%$ \\
\hline Trento & $46^{\circ} 04^{\prime} 00^{\prime \prime} \mathrm{N}$ & $11^{\circ} 07^{\prime} 00^{\prime \prime} \mathrm{E}$ & 9:27:19 & $10: 35: 38$ & $11: 47: 33$ & $64.09 \%$ \\
\hline Genoa & $44^{\circ} 24^{\prime} 40^{\prime \prime} \mathrm{N}$ & $8^{\circ} 55^{\prime} 58^{\prime \prime} \mathrm{E}$ & $9: 22: 28$ & 10:30:12 & 11:42:01 & $62.99 \%$ \\
\hline Venice & $45^{\circ} 26^{\prime} 23^{\prime \prime} \mathrm{N}$ & $12^{\circ} 19^{\prime} 55^{\prime \prime} \mathrm{E}$ & 9:28:02 & $10: 36: 25$ & $11: 48: 17$ & $61.44 \%$ \\
\hline Bologna & $44^{\circ} 29^{\prime} 38^{\prime \prime} \mathrm{N}$ & $11^{\circ} 20^{\prime} 34^{\prime \prime} \mathrm{E}$ & 9:25:30 & $10: 33: 35$ & $11: 45: 26$ & $60.59 \%$ \\
\hline Trieste & $45^{\circ} 38^{\prime} 10^{\prime \prime} \mathrm{N}$ & $13^{\circ} 48^{\prime} 15^{\prime \prime} \mathrm{E}$ & 9:30:05 & $10: 38: 37$ & $11: 50: 26$ & $60.35 \%$ \\
\hline Florence & $43^{\circ} 46^{\prime} 17^{\prime \prime N}$ & $11^{\circ} 15^{\prime} 15^{\prime \prime E}$ & $9: 24: 27$ & $10: 32: 22$ & $11: 44: 08$ & $59.15 \%$ \\
\hline Perugia & $43^{\circ} 06^{\prime} 44^{\prime \prime} \mathrm{N}$ & $12^{\circ} 23^{\prime} 20^{\prime \prime} \mathrm{E}$ & 9:25:05 & $10: 32: 57$ & $11: 44: 35$ & $56.50 \%$ \\
\hline Ancona & $43^{\circ} 37^{\prime} 00^{\prime \prime} \mathrm{N}$ & $13^{\circ} 31^{\prime} 00^{\prime \prime} \mathrm{E}$ & $9: 27: 13$ & $10: 35: 19$ & $11: 46: 56$ & $56.31 \%$ \\
\hline Rome & $41^{\circ} 53^{\prime} 35^{\prime \prime} \mathrm{N}$ & $12^{\circ} 28^{\prime} 58^{\prime \prime} \mathrm{E}$ & 9:23:45 & $10: 31: 16$ & $11: 42: 38$ & $53.76 \%$ \\
\hline Pescara & $42^{\circ} 27^{\prime} 51^{\prime \prime} \mathrm{N}$ & $14^{\circ} 12^{\prime} 51 " \mathrm{E}$ & $9: 26: 50$ & $10: 34: 38$ & $11: 45: 56$ & $53.01 \%$ \\
\hline Cagliari & $39^{\circ} 13^{\prime} 00^{\prime \prime} \mathrm{N}$ & $9^{\circ} 07^{\prime} 00^{\prime \prime} \mathrm{E}$ & 9:16:06 & $10: 22: 15$ & $11: 32: 58$ & $51.65 \%$ \\
\hline Campobasso & $41^{\circ} 33^{\prime} 40^{\prime \prime} \mathrm{N}$ & $14^{\circ} 40^{\prime} 06^{\prime \prime} \mathrm{E}$ & $9: 26: 27$ & $10: 33: 57$ & $11: 44: 57$ & $50.51 \%$ \\
\hline Naples & $40^{\circ} 50^{\prime} 50^{\prime \prime} \mathrm{N}$ & $14^{\circ} 15^{\prime} 29^{\prime \prime} \mathrm{E}$ & 9:25:06 & $10: 32: 18$ & 11:43:09 & $49.40 \%$ \\
\hline Potenza & $40^{\circ} 38^{\prime} 00^{\prime \prime} \mathrm{N}$ & $15^{\circ} 48^{\prime} 00^{\prime \prime} \mathrm{E}$ & 9:27:13 & $10: 34: 19$ & $11: 44: 48$ & $47.12 \%$ \\
\hline Bari & $41^{\circ} 07^{\prime} 31^{\prime \prime} \mathrm{N}$ & $16^{\circ} 52^{\prime} 00^{\prime \prime} \mathrm{E}$ & $9: 29: 24$ & $10: 36: 40$ & 11:47:07 & $46.93 \%$ \\
\hline Palermo & $38^{\circ} 06^{\prime} 56^{\prime \prime} \mathrm{N}$ & $13^{\circ} 21^{\prime} 41^{\prime \prime} \mathrm{E}$ & 9:47:00 & $10: 26: 41$ & $11: 36: 30$ & $44.36 \%$ \\
\hline Reggio Calabria & $38^{\circ} 06^{\prime} 52^{\prime \prime} \mathrm{N}$ & $15^{\circ} 39^{\prime} 00^{\prime \prime} \mathrm{E}$ & $9: 24: 30$ & $10: 30: 14$ & $11: 39: 33$ & $41.62 \%$ \\
\hline
\end{tabular}

Table 1. Timing and Sun's dimming of the March 20, 2015, eclipse in major Italian cities. The reported timing is in UT+1 to fit the local Italian time. 

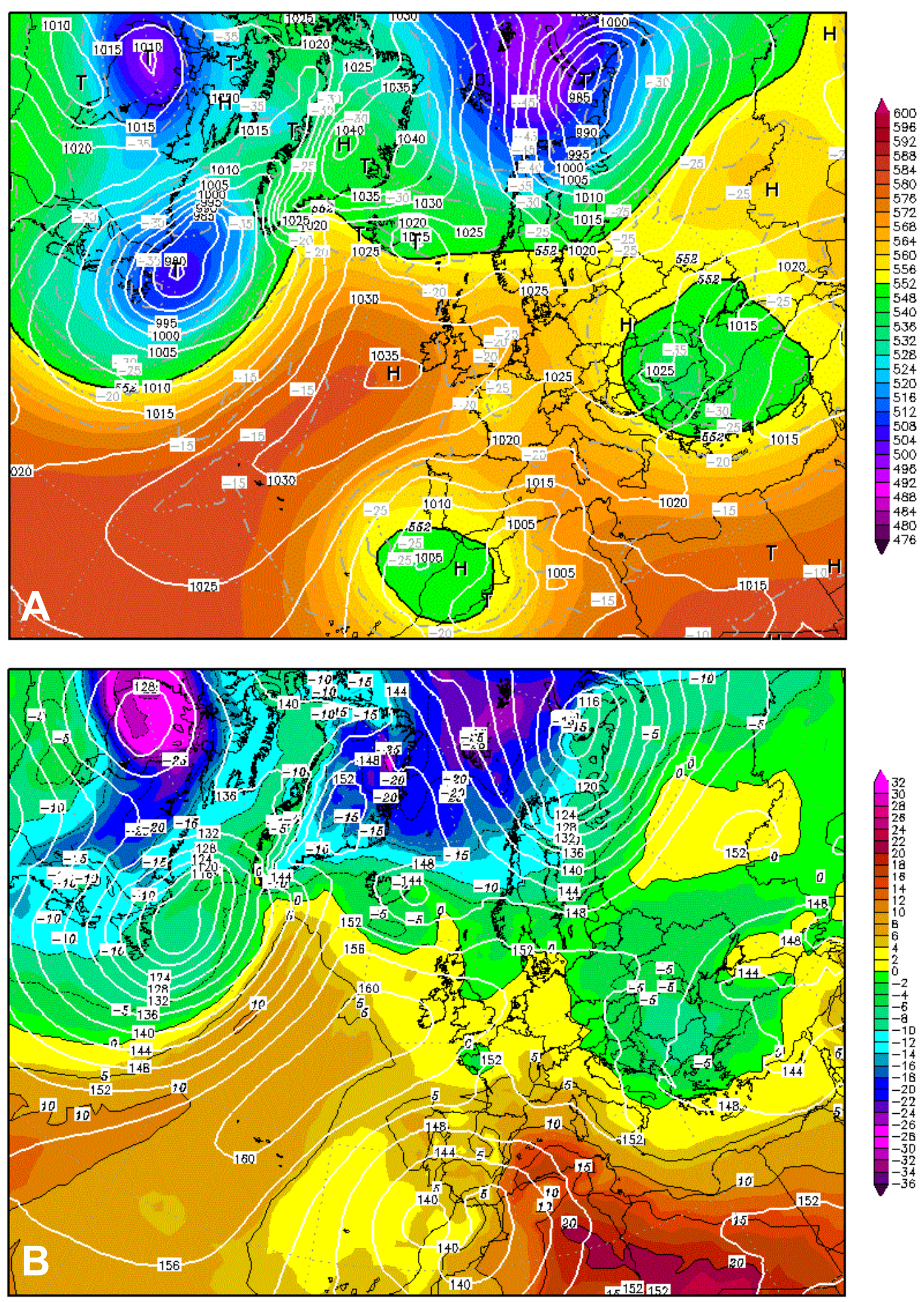

Figure 3. (A) $500 \mathrm{hPa}$ geopotential (gpdm), temperature $\left({ }^{\circ} \mathrm{C}\right)$ and sea-level pressure (hPa), and (B) 850 geopotential (gpdm) and temperature $\left({ }^{\circ} \mathrm{C}\right)$ in Europe on March 20, 2015. Figure from http:/ /www.wetterzentrale.de.

lected from three automatic stations located on the turret of the building of San Marcellino (lat. $40^{\circ} 50^{\prime} 50.2^{\prime \prime} \mathrm{N}$, long. $14^{\circ} 15^{\prime} 28.7^{\prime \prime E}$, altitude $50 \mathrm{~m}$ ). The stations are run by the following weather sensors: temperature $\left({ }^{\circ} \mathrm{C}\right)$, atmospheric pressure (hPa), relative humidity $(\%)$, wind $\operatorname{speed}(\mathrm{m} / \mathrm{s})$, wind direction $\left({ }^{\circ}\right.$ North$)$, precipitation $(\mathrm{mm})$, global and direct solar radiation $\left(\mathrm{W} / \mathrm{m}^{2}\right)$, UV radiation $\left(W / m^{2}\right)$.
Figure 5 shows the total solar irradiance and the UV irradiance records measured at the Observatory on the eclipse day. The data are 10-minute averages. The colored area highlights the period of the eclipse's occurrence in Naples from 9:25 to 11:43 local time: see Table 1 . The dimming of the surface solar and UV radiation records during the eclipse is evident. Until noon the meteorological solar radiation record is very smooth, 


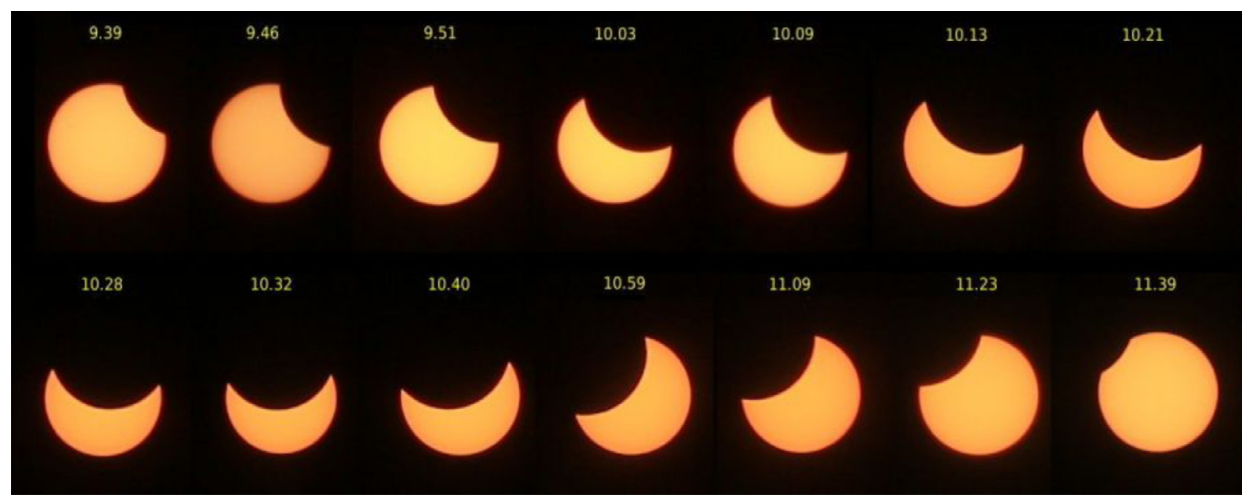

Figure 4. Set of photographs of various phases of the March 20, 2015, eclipse as observed in Pescara (central Italy). The reported timing is in UT+1 to fit the local Italian time. Photo from http: / / www.zazoom.it/ newsnotizia/ post/305603/eclissi-solare-del-2032015-osservata-daterra-e-dallo-spazio.

a fact that confirms that the sky was clean and cloudfree during the entire eclipse period.

We also note that the solar irradiance daily peak last about one hour from about 11:50 to 12:50, while the UV peak last only about $15 \mathrm{~min}$ from 11:50 to 12:05, as expected by the geographical position on Naples. This behavior could be explained by the fact that the UV band is very narrow $(280-400 \mathrm{~nm})$ compared with the band of the solar irradiance. This covers a far larger interval peaking in correspondence of the visible light at 380$750 \mathrm{~nm}$ making the irradiance measure more variable.

At the eclipse's beginning (9:25 local time) the total solar irradiance was $552 \mathrm{~W} / \mathrm{m}^{2}$. It reached a minimum of $334 \mathrm{~W} / \mathrm{m}^{2}$ at the eclipse's apex at 10:32 local time and it increased to $760 \mathrm{~W} / \mathrm{m}^{2}$ when the eclipse ended at 11:43 local time.
At the eclipse's maximum in Naples, the Sun was covered by $49.40 \%$ : see Table 1 . Without the eclipse the total solar irradiance at the surface had to be about 660 $\mathrm{W} / \mathrm{m}^{2}$, which is slightly larger than the average between the values at the beginning and at the end of the eclipse, that is, $656 \mathrm{~W} / \mathrm{m}^{2}$. Note that the observation occurred during the late morning when these indexes are expected to rise approximately linearly as indicated in the figure with dash lines.

Figure 5 shows also the UV record. At the eclipse's beginning (9:25 local time), the UV irradiance was 0.39 $\mathrm{W} / \mathrm{m}^{2}$ and it increased to $0.52 \mathrm{~W} / \mathrm{m}^{2}$ when the eclipse ended (11:43 local time). Without the eclipse's obscuration, at 10:32 the UV irradiance had to be about the average between the two values, that is $0.46 \mathrm{~W} / \mathrm{m}^{2}$. However, at the eclipse's apex at 10:32 local time the

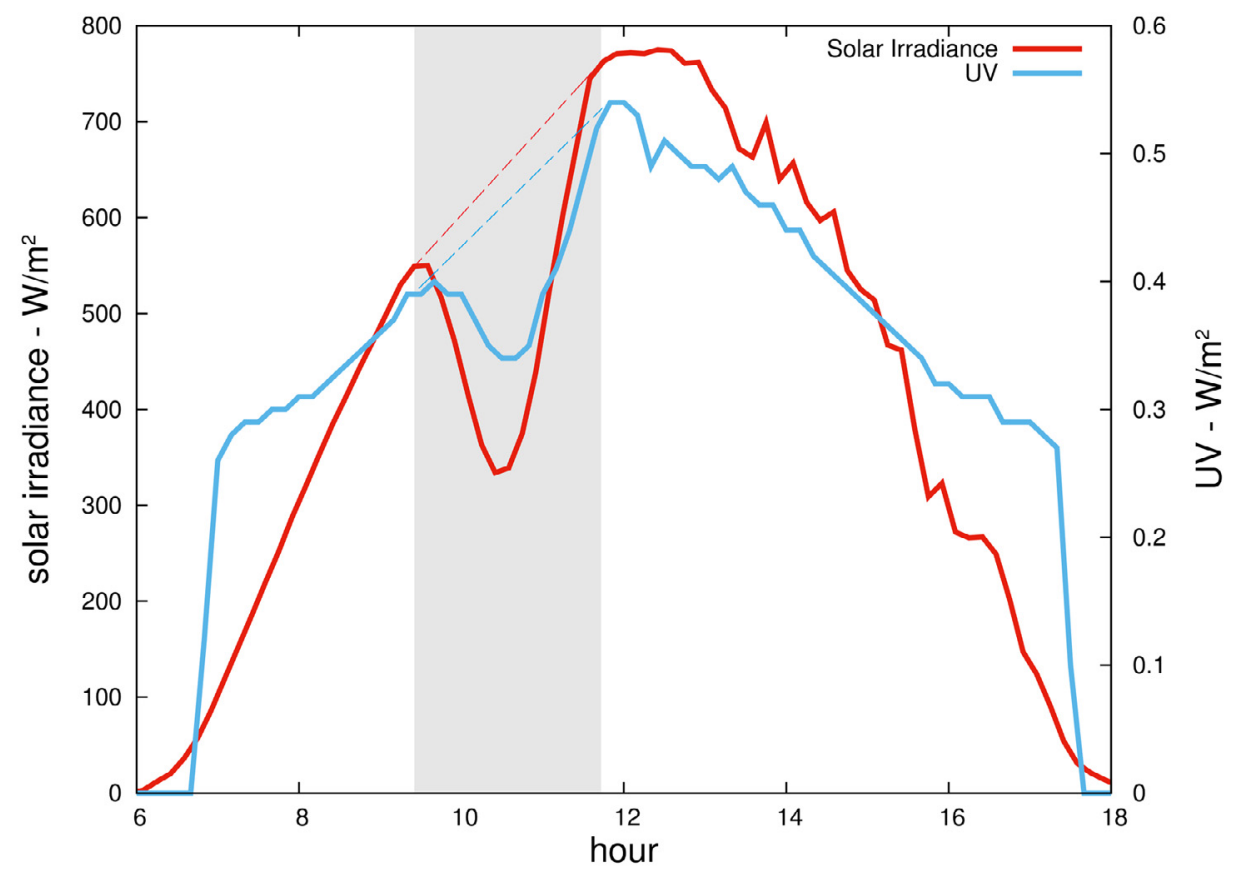

Figure 5. Total solar irradiance and UV irradiance measured in Naples on March 20, 2015. The colored area highlights the period from 9:25 to 11:43 (UT+1, local time) when the eclipse occurred in Naples: see Table 1. The blue and red broken lines show approximately the expected normal behavior of the UV and solar irradiance at the same day without eclipse. 
measured UV irradiance was $0.34 \mathrm{~W} / \mathrm{m}^{2}$, that is about $75 \%$ of the above no-eclipse expected value despite about $50 \%$ of the Sun was covered by the Moon.

An UV dimming by only $25 \%$ suggests that about $50 \%$ of the UV reaching the surface in Naples was direct light while the leftover $50 \%$ of the UV surface radiation was scattered light. ${ }^{(2)}$ This result could be explained as follows. An eclipse can only block the direct UV light (DUV) because only this component is screened by the solar eclipse, whose percent in Naples was about $\mathrm{SE}=50 \%$. Because the observed UV radiation (OUV) at the surface was $75 \%$ of the expected noeclipse value, $50 \%$ of the UV surface radiation has to be direct UV light (DUV) and 50\% scattered UV light (SUV), which is not blocked by the eclipse. In fact, we have that the observed UV radiation during the eclipse must be made of two components as follows:

$O U V=D U V \cdot S E+S U V=50 \% \cdot 50 \%+50 \%=75 \%$.

Figure 6 summarizes a number of meteorological variables (temperature, relative humidity, wind speed and atmospheric pressure) measured in Naples on March 20, 2015. The meteorological effects of the eclipse, occurred from 9:25 to 11:43 local time, are quite evident in these records. Figure $6 \mathrm{~A}$ shows that during the eclipse, from 9:25 to about 11:00 local time the temperature
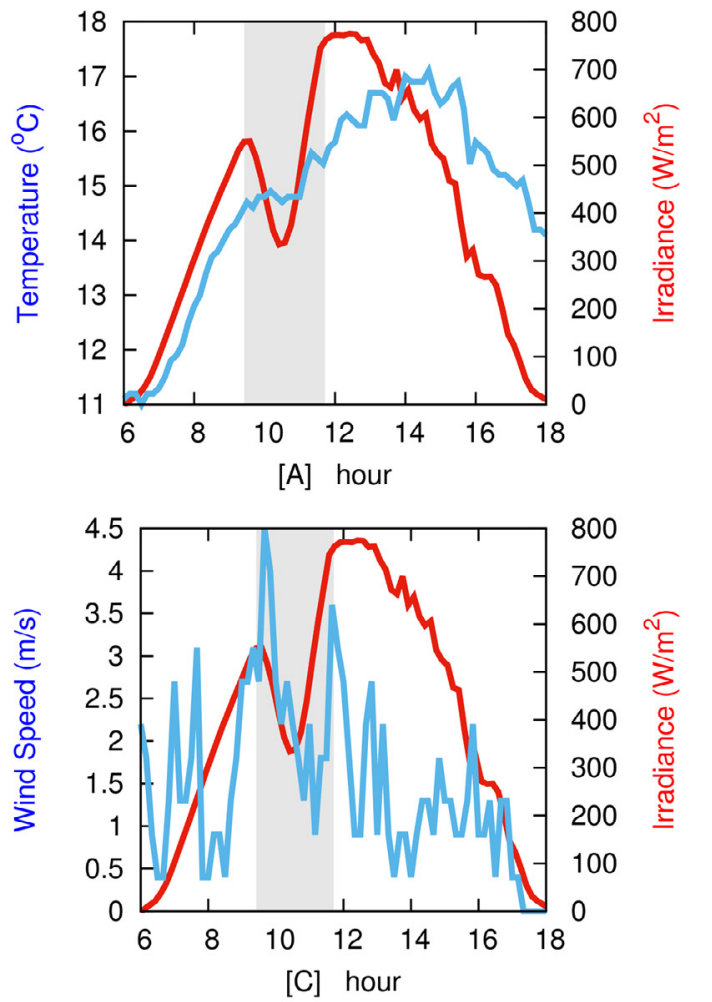

first slightly increased from about $14.7^{\circ} \mathrm{C}$ to $14.9^{\circ} \mathrm{C}$ and then decreased again to about $14.8^{\circ} \mathrm{C}$. Thus, during the first 1.5 hour of the eclipse the temperature stayed approximately fixed at about $14.8^{\circ} \mathrm{C}$. This temperature standstill is indirectly confirmed by the relative humidity that also halted its morning natural decrease and stayed fixed at about $42.5 \%$. In fact, under moderate wind condition the temperature and the relative humidity are inversely related. After the eclipse, at about 12:00, the temperature raised to about $16.0^{\circ} \mathrm{C}$. Using a simple linear interpolation it is possible to calculate that without the eclipse at 10:30 the temperature had to be $0.6-0.7^{\circ} \mathrm{C}$ warmer than at $9: 30$, that is about $15.3-15.4^{\circ} \mathrm{C}$. Thus, in this occasion the $49.4 \%$ eclipse observed in Naples has caused a cooling of about 0.5$0.6^{\circ} \mathrm{C}$ relative to the expected temperature.

The stationary climatic condition observed during the eclipse from 9:25 to 11:00 can be used to roughly calculate the average emissivity $\epsilon$ of the city of Naples by taking into consideration that the Meteorological Observatory of San Marcellino is located nearly in the center of the city. We use the Stefan-Boltzmann law:

$$
J=\varepsilon \sigma T^{4}
$$

Here, the Stefan's constant is $\sigma=5.67 * 10^{-8} \mathrm{Wm}^{-2} \mathrm{~K}^{-4}$ and the temperature is $\mathrm{T}=14.8^{\circ} \mathrm{C}+273.15^{\circ} \mathrm{C}=287.95 \mathrm{~K}$.
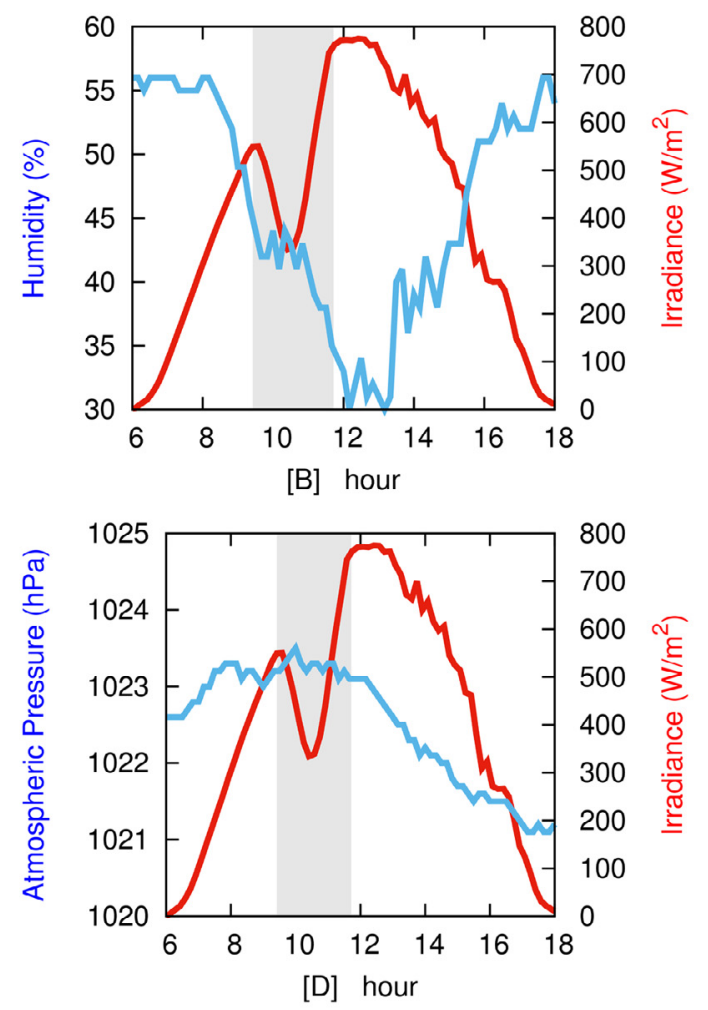

Figure 6. Meteorological variables versus solar irradiance values measured in Naples on March 20, 2015. The colored area highlights the period from 9:25 to 11:43 (UT+1, local time) when the eclipse occurred: see Table 1. (A) Temperature; (B) humidity; (C) wind speed; (D) atmospheric pressure. 
The calculation is based on the assumption that the infrared average radiation $J$ emitted by the city had to be equal to the incoming solar radiation because during the eclipse the temperature staid nearly constant, which indicates a balance between the two radiations. Thus, we have $J=334 \mathrm{~W} / \mathrm{m}^{2}$. Using Equation (2) and under the above hypothesis we found that the average emissivity of the city of Naples is about $\varepsilon=0.86$.

During the eclipse, the wind speed decreased from about $3.0 \mathrm{~m} / \mathrm{s}$ to about $1.5 \mathrm{~m} / \mathrm{s}$, which could also be a consequence of the missing increase of the temperature. Probably, as the incoming radiation decreased, a moderate temperature inversion between the surface and higher atmospheric layers occurred and partially blocked the lower layer air circulation. To test this hypothesis, we compared the temperature values measured at the $\mathrm{Ob}$ servatory of San Marcellino versus those measured at the Observatory located at Monte Sant'Elmo, which is located at $250 \mathrm{~m}$ asl about on the vertical of San Marcellino: see Table 2. We observed that during the eclipse, between 10:00 and 11:00, the potential temperature difference between Sant'Elmo and San Marcellino was $0.2^{\circ} \mathrm{C}$ higher than before and after the eclipse. This indicates a moderate reduction of the thermodynamic instability that could be consistent with the reduced wind stress.

The wind was coming mostly from North and no direction change was observed during the eclipse. The wind direction switched to South since 13:30 local time. Finally, the atmospheric pressure remained relatively constant at $1023.3 \mathrm{hPa}$ from 8:00 to 11:30 local time: it decreased after 11:30 local time since the eclipse ended.

We also suggest a simple methodology to be used by meteorologists to improve the weather forecast in case of an eclipse. In fact, the models used to forecast weather do not take into account the occurrence of an eclipse and meteorologists may be interested in a simple empirical method to correct the theoretical meteorological temperature forecast by a certain eclipse cooling effect $\Delta T_{\text {eclipse }}$. Let us suppose that: (1) the city of Naples is indicative of other cities and locations relatively similar and close to the coast such as most Italian cities; (2) in such locations, an eclipse-related reduction

\begin{tabular}{cccc}
\hline $\begin{array}{c}\text { Time } \\
\text { interval }\end{array}$ & Sant'Elmo & San Marcellino & $\begin{array}{c}\text { Temperature } \\
\text { gradient }\end{array}$ \\
\hline 8:30-9:30 & $11.9{ }^{\circ} \mathrm{C}$ & $14 .{ }^{\circ} \mathrm{C}$ & $-2.4{ }^{\circ} \mathrm{C}$ \\
$10: 00-11: 00$ & $12.6{ }^{\circ} \mathrm{C}$ & $14.8^{\circ} \mathrm{C}$ & $-2.2{ }^{\circ} \mathrm{C}$ \\
$11: 30-12: 30$ & $13.5^{\circ} \mathrm{C}$ & $15.9{ }^{\circ} \mathrm{C}$ & $-2.4{ }^{\circ} \mathrm{C}$ \\
\hline
\end{tabular}

Table 2. Air temperature gradient between Sant'Elmo and San Marcellino Meteorological Observatories. The data from Sant'Elmo were taken from http://www.campanialive.it. of the total solar irradiance by about $326 \mathrm{~W} / \mathrm{m}^{2}$ from the expected $660 \mathrm{~W} / \mathrm{m}^{2}$ to $334 \mathrm{~W} / \mathrm{m}^{2}$ in one hour causes a cooling respect to the expected temperature by about $0.55^{\circ} \mathrm{C}$ as observed in Naples. The empirical equation must be calibrated against the expected temperature values at the times of the our observed eclipse in Naples, when the temperature would have increased by about $0.65^{\circ} \mathrm{C}$ from 9:30 to 10:30 if no eclipse had occurred. Thus, if $T_{\text {expected }}$ is the forecast temperature at the apex of the eclipse in a given location, $T_{9: 30}$ is the expected temperature at that location at 9:30 local time, $T_{10: 30}$ is the expected temperature at that location at 10:30 local time, SSI is the expected solar irradiance at the surface in absence of the eclipse at the time of the eclipse and SE is the obscuration percent of the eclipse at the same location, then the temperature $T_{\text {eclipse }}$ at the apex of the eclipse at that location should be about

$$
\begin{gathered}
T_{\text {eclipse }}=T_{\text {expected }}-\Delta T_{\text {eclipse }} \\
\approx T_{\text {expected }}-0.55 \frac{T_{10: 30}-T_{y: 30}}{0.65} \cdot \frac{S E}{0.494} \cdot \frac{\gamma \cdot S S I}{600} \\
\approx T_{\text {expected }}-0.0026\left(T_{10: 30}-T_{y: 30}\right) \cdot S E \cdot \gamma \cdot S S I
\end{gathered}
$$

In fact, if $S E=0 \%$ (that is an eclipse does not occur) then $T \approx T_{\text {expected }}$; if $S E=49.4 \%=0.494$, as observed in Naples in this occasion, then using the expected temperature values $T_{9: 30}=14.7^{\circ} \mathrm{C}$ and $T_{\text {expected }}=T_{10: 30}=$ $15.35^{\circ} \mathrm{C}$ and the expected solar irradiance at the surface $S S I=660 \mathrm{~W} / \mathrm{m}^{2}$ reported above, Equation (3) gives $T \approx T_{\text {expected }}-0.55 \approx 14.8^{\circ} \mathrm{C}$, as observed. The eclipse cooling effect $\Delta \mathrm{T}_{\text {eclipse }}$ in Equation (3) should be corrected by a given factor $\gamma$ measuring the average daily variation of SSI in presence of clouds. For example, if during the eclipse the sky remains as cloudy as during the times of reference at 9:30 and 10:30 local time $\gamma \approx 1$; if the cloudiness of the sky during the eclipse was lower than during the times of reference at 9:30 and 10:30 local time $\gamma$ would be larger than 1, and vice versa.

\section{Discussion and conclusion}

Meteorological parameters and solar and UV surface irradiance indices were measured in Naples, central Italy, during the partial $(\sim 50 \%)$ equinoctial solar eclipse occurred on March 20, 2015. The observations were optimal for the purposes of this study because the sky was clear and cloud free.

During the eclipse, which last about two hours from 9:25 to 11:43 local Italian time, the surface solar irradiance dropped by about $50 \%$ in about a hour, at 10:32 local time in correspondence of apex of the eclipse. This abrupt irradiance decrease caused a halt in both the urban temperature and relative humidity. Without 
the eclipse, these indices had to increase and decrease, respectively, due to their daily cycle.

The stationary temperature and relative humidity were likely also favored by Naples' surrounding environment: mainly by the thermal damping effect of the sea-water influence. In fact, a similar response occurred in a number of Greek coastal sites during the total solar eclipse of March 29, 2006 [Founda et al. 2007]. The sea thermal damping effect is indirectly evident in Figure $6 \mathrm{~A}$ showing that in Naples the temperature daily peak occurs 2-3 hours after the peak of the surface irradiance, that is at 14:00-15:00 while in Naples the theoretical surface irradiance peak occurs about 10 minutes after noon. On the contrary, the meteorological effects of an eclipse are more significant in arid lands far from the sea coast, where water thermal damping effect is less significant. For example, during a partial $(\sim 60 \%)$ eclipse in 2005 in the Makkah Region, a location far from the coast in South Arabia, the temperature decreased slightly by about $1{ }^{\circ} \mathrm{C}$ and the relative humidity increased [Anbar 2006]. Significant eclipse-modified boundary layers were also observed in New Mexico, U.S.A., during the May 10, 1994, partial (94\%) solar eclipse over the desert [Eaton et al. 1997].

The stationary temperature and relative humidity occurred during the eclipse could also be used to estimate that the average emissivity of the city of Naples is $\varepsilon=0.86$. We observe that this result is realistic because Naples is densely built and concrete has an emissivity of about $\varepsilon=0.85$. Typically, general constructions materials and asphalts have an emissivity between 0.80 and 0.95 [Sobrino et al. 2012, tab. 7 and fig. 4]. As a further confirmation of such an approach, we repeated the analysis using the data from the observatory of Casamicciola in Ischia known as the green island. We found an emissivity equal to about 0.96 that corresponds to the value for a mostly green surface with few constructions.

We have also observed that surface wind-speed, whichwas relativelyweak, decreased during the eclipse from about $3.0 \mathrm{~m} / \mathrm{s}$ to about $1.5 \mathrm{~m} / \mathrm{s}$. This effect was also observed in most sites in Greece during the total solar eclipse of March 29, 2006, as a result of the partial cooling and/or stabilization of the atmospheric boundary layers [Founda et al. 2007]. Thus, likely during the eclipse a moderate thermal inversion occurred between the surface and higher atmospheric boundary layers and this was observed also in Naples by comparing the temperature records of the Observatories at Sant'Elmo and San Marcellino, located about on the same vertical $200 \mathrm{~m}$ apart.

We have compared the surface total solar irradiance record against the surface UV record. UV radiation at the surface depends on the total ozone air column.
On Naples the total ozone integrated vertical profile column density was about 350 Dobson units according to an estimate based on the Ozone Measurement Instrument (OMI) (http: / / www.temis.nl/protocols / O3total. $\mathrm{html})$. While at the eclipse peak the surface total solar irradiance value dropped by about $50 \%$, which is a percentage consistent with the Moon screening of the Sun, the UV record dropped only by $25 \%$, that is equal to the $75 \%$ of the expected value if the eclipse had not occurred. The result confirms a strong wavelength dependency of the atmospheric response to surface solar irradiance spectra [Rayleigh 1899] where high frequency light is scattered more and, therefore, should be less screened by an eclipse than low frequency light. In particular, we have determined that our observation implies that about $50 \%$ of the UV radiation reaching the surface in Naples is direct light and 50\% was scattered light. Our result could be typical of the orography of Naples. Future studies could determine whether and how this property could be generalized. For example, it could be investigated the influence of the tropospheric ozone, which with clear sky and in metropolitan areas could have play an important UV diffusion.

Finally, we have proposed a simple methodology, Equation (3), to be used by meteorologists to improve the weather forecast in case of an eclipse. The equation attempts to evaluate the cooling associated to a generic eclipse as a proportion relative to the relevant parameters measured in Naples in this occasion. The fact that theMarch 20, 2015, partial eclipse obscured the Sun in Naples by about $50 \%$ and had its apex at about 10:30, that is during the middle of the warming phase of the temperature diurnal cycle from about 7:00 to 14:00, could make Equation (3) a mean estimate that could work in most cases. According to Equation (3), if on March 20, 2015, the eclipse was total, in Naples the temperature would have dropped by about $1.1^{\circ} \mathrm{C}$ respect to the expected $15.3-15.4^{\circ} \mathrm{C}$. Thus, we expect that in Italy and in other comparable locations an eclipse could cause a cooling of the order of $1^{\circ} \mathrm{C}$ respect to the expected temperature in absence of an eclipse. According to Equation (3), the eclipse effect should be greater in locations where the diurnal temperature cycle is greater than in Naples on March 20, and vice versa.

An extensive testing of Equation (3) is left to further study. However, herein we can approximately test this empirical equation against some of the results already published in the literature. For example, Founda et al. [2007] studied the effect of the total solar eclipse (from 100\% to 75\%) of March 29, 2006, on meteorological variables in Greece. In the city of Kastelorizo (lat. $36^{\circ} 9^{\prime} \mathrm{N}$, long. $29^{\circ} 35^{\prime} \mathrm{E}$, a small Greek island near the coast of southern Turkey) the eclipse obscuration was 
nearly $100 \%$ and, at the time of the eclipse (about 10:53 UT, 12:53 local time), the solar irradiance at the surface dropped from the expected value $S S I \approx 900 \mathrm{~W} / \mathrm{m}^{2}$ to nearly zero. From 9:30 to 10:30 local time (7:30 to $8: 30$ UT) the temperature increased by about $1.4^{\circ} \mathrm{C}(\mathrm{cf}$. Founda et al. [2007], fig. 3). Thus, Equation (3) predicts an eclipse related cooling of about $3.3^{\circ} \mathrm{C}$ relative to the expected temperature in absence of the eclipse: by visual interpolation of Figure 3 in Founda et al. [2007] this is what appears to have occurred. Similarly, in the city of Thessaloniki (lat. $40^{\circ} 38^{\prime} \mathrm{N}$, long. $22^{\circ} 57^{\prime} \mathrm{E}$, a city in the north of Greece) the eclipse obscuration was nearly $75 \%$. At the time of the eclipse (about 10:49 UT, 12:49 local time), the solar irradiance at the surface dropped significantly from the expected value $S S I \approx 800 \mathrm{~W} / \mathrm{m}^{2}$. From 9:30 to 10:30 local time (7:30 to $8: 30 \mathrm{UT}$ ), the temperature increased by about $3.0^{\circ} \mathrm{C}$ (cf. Founda et al. [2007], fig. 3). Thus, Equation (3) predicts an eclipse related cooling of about $4.7^{\circ} \mathrm{C}$ relative to the expected temperature in absence of the eclipse, which is again about what appears to have occurred (cf. Founda et al. [2007], fig. 3). Although approximate, we believe that these results are remarkable given the simplicity of Equation (3) that further study could improve and better calibrate.

\section{Notes}

(1). The Meteorological Observatory is attached to the Department of Earth Sciences, Environment and Resources and is located in the center of Naples, Italy, in Largo S. Marcellino. It was established by dictatorial decree of Giuseppe Garibaldi, on October 29, 1860, at the request of Prof. Luigi Palmieri, holder of the first chair of Meteorology after the unification of Italy in 1860. The Meteorological Observatory of San Marcellino is, therefore, the highest institution regarding the knowledge of meteorological events of the city of Naples and one of the major meteorological centers in Italy.

(2). Rayleigh [1899] found that the particle scattering of electromagnetic radiation is proportional to the fourth power of the frequency so that in air high frequency radiation is more scattered than the low frequency one.

\section{References}

Anbar, O.M.Y. (2006). Solar eclipse effects on the air layer near the surface over Makkah Region, Journal of King Abdulaziz University-Meteorology, Environment and Arid Land Agriculture Sciences, 18 (2), 47-59.

Di Cristo, R., A. Mazzarella and R. Viola (2007). An analysis of heat index over Naples (Southern Italy) in the context of European heat wave of 2003, Nat. Hazards, 40, 373-379; doi:10.107/s11069-006-0033-7.

Eaton, F., J. Hines, W. Hatch, R. Cionco, J. Byers, D. Garvey and D. Miller (1997). Solar eclipse effects observed in the planetary boundary layer over a desert, Bound.-Lay. Meteorol., 83, 331-346.

Founda, D., D. Melas, S. Lykoudis, I. Lisaridis, E. Gera- sopoulos, G. Kouvarakis, M. Petrakis and C. Zerefos (2007). The effect of the total solar eclipse of 29 March 2006 on meteorological variables in Greece, Atmos. Chem. Phys., 7, 5543-5553.

Kazadzis, S., A.F. Bais, M. Blumthaler, A. Webb, N. Kouremeti, R. Kift, B. Schallhart and A. Kazantzidis (2007). Effects of total solar eclipse of 29 March 2006 on surface radiation, Atmos. Chem. Phys., 7, 5775-5783.

Kazantzidis, A., A.F. Bais, C. Emde, S. Kazadzis and C.S. Zerefos (2007). Attenuation of global ultraviolet and visible irradiance over Greece during the total solar eclipse of 29 March 2006, Atmos. Chem. Phys., 7, 5959-5969.

Mazzarella, A., and A. Giuliacci (2011). Urbanizationinduced variations in air temperature and rainfall in Naples - Southern Italy, Romanian Journal of Climatology, 2, 67-77.

Muraleedharan, P.M., P.G. Nisha and K. Mohankumar (2010). Effect of January 15, 2010 annular solar eclipse on meteorological parameters over Goa, India, J. Atmos. Sol.-Terr. Phy., 73, 1988-1998.

Palumbo, A., and A. Mazzarella (1984). Local recent changes in extreme air temperatures, Clim. Change, 6, 303-309.

Sobrino, J.A., R. Oltra-Carrió, J.C. Jiménez-Munoz, Y. Julien, G. Sòria, B. Franch and C. Mattar (2012). Emissivity mapping over urban areas using a classification-based approach: Application to the Dualuse European Security IR Experiment (DESIREX), Int. J. Appl. Earth Obs., 18, 141-147.

Strutt, J. (Lord Rayleigh) (1899). On the transmission of light through an atmosphere containing small particles in suspension, and on the origin of the blue of the sky, Philosophical Magazine, series 5, 47, 375-394.

Tzanis, C. ,C. Varotsos and L. Viras (2008). Impacts of the solar eclipse of 29 March 2006 on the surface ozone concentration, the solar ultraviolet radiation and themeteorological parameters at Athens, Greece, Atmos. Chem. Phys., 8, 425-430.

Zerefos, C., N. Mihalopoulos and P. Monks, eds. (2007). The total solar eclipse of 2006 and its effects on the environment, Atmos. Chem. Phys., Special issue.

\footnotetext{
${ }^{\star}$ Corresponding author: Adriano Mazzarella, Osservatorio Meteorologico, Università di Napoli Federico II, Dip. di Scienze della Terra, dell'Ambiente e delle Risorse, Naples, Italy; email: adriano.mazzarella@unina.it.

(C) 2016 by the Istituto Nazionale di Geofisica e Vulcanologia. All rights reserved.
} 